\title{
Distribution Characteristics of Undergraduate Biomedical Engineering Specialty in Chinese Mainland Colleges and Universities
}

Shilu Wang: Jiangsu Provincial Key Laboratory of Coastal Wetland Bioresources and Environmental Protection, School of Pharmacy, Yancheng Teachers University, Jiangsu, China.

\begin{abstract}
The aim of this research is to determine the distribution characteristics of undergraduate biomedical engineering specialty in Chinese mainland colleges and universities. This study used induction and statistics to analyze the geographical and professional categories of 125 colleges and universities. The result of this research shows that (1)this major is more concentrated in capital / provincial capital cities, (2)the professional courses generally tend to be related to medical equipment.
\end{abstract}

Key words: Biomedical engineering, Distribution, Central cities.

\section{Introduction}

Biomedical engineering is frontier interdiscipline which combines biology, medicine and engineering technology to investigate of the medical problems of human body from an engineering point of view. Undergraduate biomedical engineering education in mainland China started in the late 1970s. After 40 years of development, there are more than 100 colleges and universities offering this specialty for undergraduates (Gong, Gu, \& Mei, 2011).

Based on the background and characteristics of each school, the subject of biomedical engineering is generally divided into three directions. The first direction of subject, which is based on the development of electronic information engineering, mainly includes biomedical instruments, biomedical signal detection and processing, biomedical information calculation and analysis, biomedical imaging and image processing analysis, biomedical system modeling and simulation, clinical treatment and rehabilitation engineering optimization methods, operation planning image simulation, image guiding surgery and radiotherapy optimization. The second direction based on the development of mechanics, mainly includes biomechanics, sports biomechanics, computational biomechanics and microscale cellular biomechanics. The third direction based on the development of chemical material engineering, includes biomaterials, tissue engineering and artificial organs, biochemical effects of physical factors, etc (Li, Jing, \& Yu, 2015).

This paper introduces the distribution of undergraduate biomedical engineering specialty in Chinese International Journal of Educational Studies Vol. 1, No. 4, pp. 270-273

\section{Regions}

The list of colleges and universities offering undergraduate biomedical engineering majors in mainland China comes from the website http://www.ccutu.com/69215.html. 
Table-1. Regional Distribution of Biomedical Engineering Undergraduate Specialty

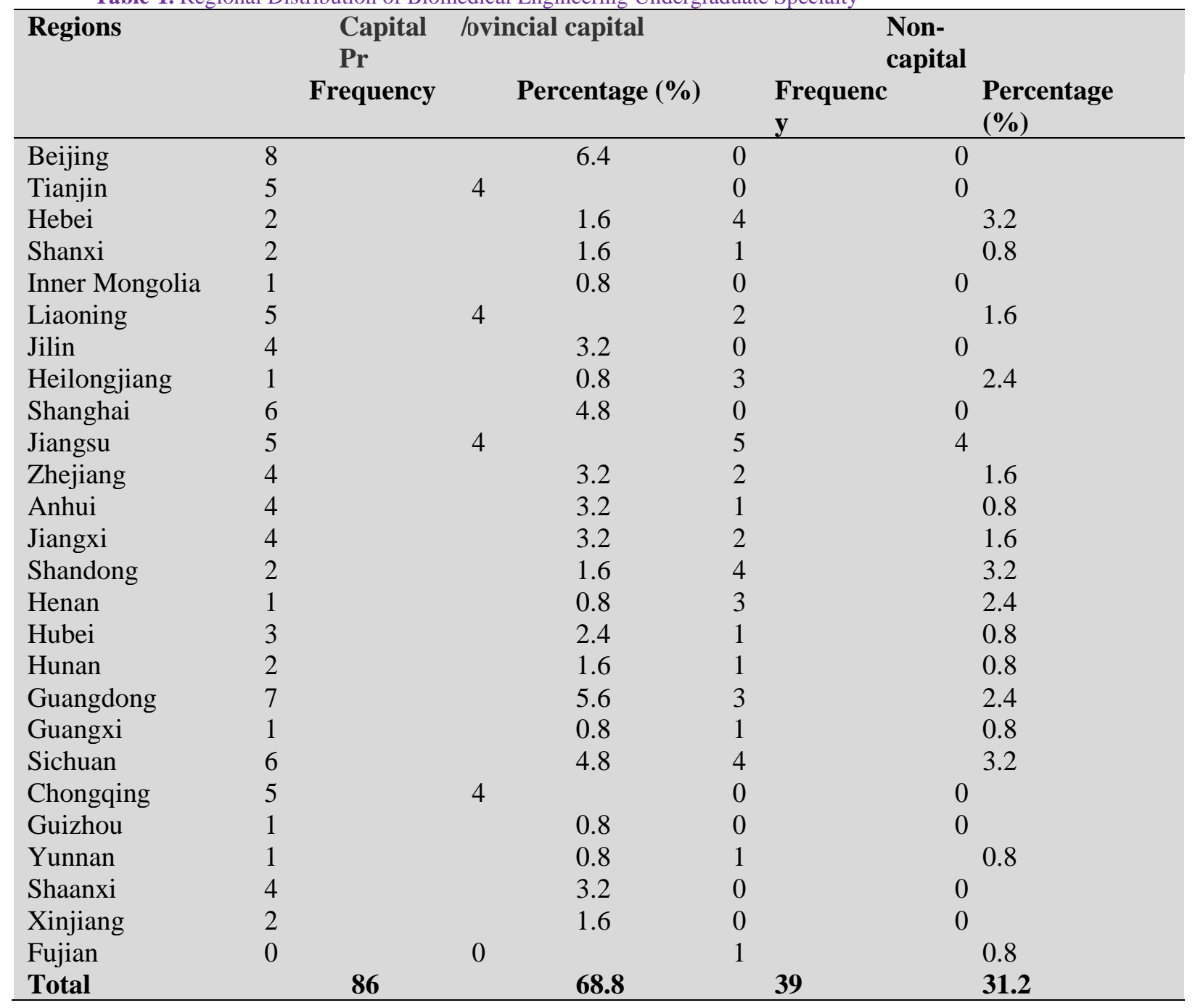

In terms of the total number of undergraduate majors in biomedical engineering, Jiangsu, Guangdong and Sichuan all have 10 colleges and universities, with the largest number. In terms of capital / provincial capital, Beijing as national capital has the largest number 8, followed by 7 in Guangzhou, 6 in Shanghai and Chengdu. There are 86 colleges and universities in capital / provincial capital, accounting for $66.8 \%$, while the number in non-capital cities is 39 , accounting for $31.2 \%$ of the total number. In order to figure out the significance of difference between capital / provincial capital('capital' in short) and non-capital cities, it is necessary to statistically analyze. The frequency data was analyzed by using SPSS (nonparametric tests for related samples).

Table-2. Descriptive Statistics

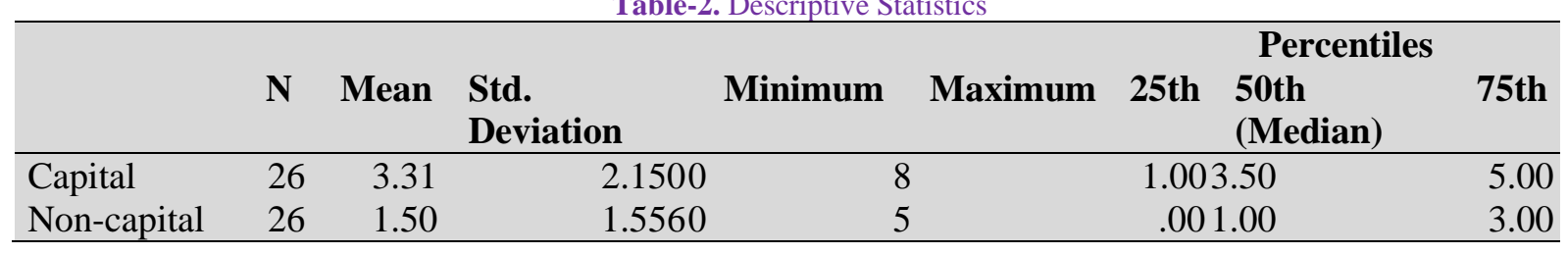


Table-3. Wilcoxon Signed Ranks Test

\begin{tabular}{|c|c|c|c|c|}
\hline & & $\mathbf{N}$ & Mean Rank & Sum of Ranks \\
\hline \multirow[t]{4}{*}{ Non-capital - Capital } & Negative Ranks & $18^{\mathrm{a}}$ & 12.94 & 233.00 \\
\hline & Positive Ranks & $5^{b}$ & 8.60 & 43.00 \\
\hline & Ties & $3^{c}$ & & \\
\hline & Total & 26 & & \\
\hline
\end{tabular}

a. Non-capital < Capital

b. Non-capital $>$ Capital

c. Non-capital $=$ Capital

\begin{tabular}{|c|c|}
\hline & Non-capital - Capital \\
\hline $\mathrm{Z}$ & $-2.914^{b}$ \\
\hline Asymp. Sig. (2-tailed) & .004 \\
\hline
\end{tabular}

Note:

a. Wilcoxon Signed Ranks Test

b. Based on positive ranks.

From Table 2, it can be seen that the average number in capital cities is 3.31 and in non-capital cities is 1.50. The average number in capital cities is higher than in non-capital cities. The phenomenon of colleges and universities gathering in national and regional political centers is prominent in mainland China. In fact, there are 15 administrative districts whose first ratio exceeds 0.5 , indicating that more than half of the students in these districts are concentrated in a central city. Some even concentrated in the provincial capital city and the first ratio is 1 (Wu \& Luo, 2012). Although only 125 of total 743 colleges and universities offer this major, the concentration trend is reflected in the distribution of biomedical engineering specialty as well. As showed in Table 3, of the 26 administrative districts with this major, 18 had a ratio of more than $0.5,3$ were equal to 0.5 , and only 5 were less than 0.5 . The results of Wilcoxon signed ranks test statistics (Table 4 ) showed that $\mathrm{P}=0.004<0.05$, which meant number in capital cities is significantly higher than in non-capital cities. This result also supports the previous point of view.

\section{Directions of Specialty}

The undergraduate course of biomedical engineering has been developing rapidly in mainland China. In addition to the transformation from established majors, there are many new ones that have been set up in recent years. Because biomedical engineering has typical cross-character and huge knowledge system, it requires cooperation in various directions. Biomedical engineering specialties set up in different colleges and universities have their own characteristics (Chen, 2011). By browsing the websites of all 125 colleges and universities, the content of undergraduate courses in biomedical engineering offered by them is divided into three categories (as described in the introduction), and the results are shown in Table 5.

The curriculum design of undergraduate education of biomedical engineering emphasizes the specialty and technology, which belongs to the mode of specialized talents training, and the cross-disciplinary degree of the curriculum is low. 118 colleges and universities offer courses related to medical instruments and equipment, while 25 offer courses around biomechanics or biomaterials. Few colleges and universities have independent school of biomedical engineering, and most have this major in computer school, electronic information school, medical school, or life sciences school. Although some schools offer similar courses, the actual programs vary considerably. For example, some schools allow students to choose the direction of research in their senior grades, some schools arrange for senior students to connect with overseas colleges and universities, and some schools arrange for senior students to go to hospitals for internships. 18 colleges and universities offering 2 or more categories courses are all located in capital / provincial capital cities. This also reflects the trend of regional concentration of the major on the other hand. Presumably colleges and universities in central cities have sufficient resources to support the development of interdisciplinary disciplines.

International Journal of Educational Studies 2018

DOI: 10.53935/2641-533x.v1i4.95 Funding: This study received no specific financial support.

Received: 14 August 2018

Revised: 10 October 2018

Accepted: 16 November 2018

Published: 28 December 2018

2018 by the authors: licensee Academic

Publishing Group

$\mid 272$ 
Table-5. Categories of Colleges and Universities

\begin{tabular}{|c|c|}
\hline Categories & Colleges and Universities \\
\hline $1,2,3$ & $\begin{array}{l}\text { Peking University, Beijing University of Technology, Shanghai Jiao Tong } \\
\text { University, Henan University of Science and Technology, Southern University of } \\
\text { Science and Technology (5) }\end{array}$ \\
\hline 1,2 & $\begin{array}{l}\text { Beijing Institute of Technology, Capital Medical University, Shanghai University } \\
\text { of Traditional Chinese Medicine (3) }\end{array}$ \\
\hline 1,3 & $\begin{array}{l}\text { Shenyang University of Technology, China Medical University, Nanjing } \\
\text { University, Southeast University, Zhejiang University, Huazhong University of } \\
\text { Science and Technology, Sun Yat-sen University, South China University of } \\
\text { Technology, Liaoning Ho's Medical College (9) }\end{array}$ \\
\hline & Taiyuan University of Technology (1) \\
\hline $\begin{array}{l}2,3 \\
3\end{array}$ & $\begin{array}{l}\text { Beijing University of Chemical Technology, Shenyang Pharmaceutical } \\
\text { University, Yancheng Teachers University, Hubei University of Technology, } \\
\text { Jinan University, Sichuan University, Southwest Jiaotong University (7) }\end{array}$ \\
\hline 1 & Others (100) \\
\hline
\end{tabular}

\section{Conclusion}

The distribution of biomedical engineering specialty in mainland China shows two major trends: one is the geographical position tends to be the political center city, the other is that the professional direction tends to set up the related disciplines around medical instruments.

\section{References}

Chen, Z. (2011). Discussion on training characteristics of biomedical engineering talents. Scientific Consult, 13, 115-116.

Gong, Z., Gu, N., \& Mei, H. (2011). Comparison and enlightenment of undergraduate education in biomedical engineering between China and America. Modern Education Science, 5, 132-136.

Li, H., Jing, B., \& Yu, H. (2015). Investigation on discipline construction of biomedical engineering. Beijing Biomedical Engineering, 34(6), 626-629.

$\mathrm{Wu}$, H., \& Luo, Y. (2012). Vertical distribution structure of colleges and universities in China: The phenomenon of assembling in political centers. Modern Education Management, 5, 11-16. 